\title{
The influence of DLC coating on EHL friction coefficient
}

\author{
M. Björling · P. Isaksson • P. Marklund • R. Larsson
}

Received: date / Accepted: date

\begin{abstract}
High hardness, high elastic modulus, low friction characteristics, high wear and corrosion resistance, chemical inertness and thermal stability are factors that make diamond like carbon (DLC) coatings the subject of many studies. For the same reasons they also seem suitable for use in, amongst others, machine components and cutting tools. While most studies in literature focus on the influence of coatings on wear and friction in boundary lubrication and pure sliding contacts, few studies can be found concerning rolling and sliding EHL friction, especially in the mixed and full film regime. In the present paper tests are carried out in a Wedeven Associates Machine (WAM) tribotester where an uncoated ball and disc pair is compared to the case of coated ball against uncoated disc, coated disc against uncoated ball, and coated disc against coated ball. The tests are conducted at two different temperatures and over a broad range of slide to roll ratios and entrainment speeds. The results are presented as friction maps
\end{abstract}

\section{Björling}

Division of Machine Elements, Department of Engineering Science and Mathematics, Luleå University of Technology, Luleå, SE-97187 Sweden

Tel.: +46920491281

E-mail: marcus.bjorling@ltu.se

P. Isaksson

Division of Machine Elements, Department of Engineering Science and Mathematics, Luleå University of Technology, Luleå, SE-97187 Sweden

P. Marklund

Division of Machine Elements, Department of Engineering Science and Mathematics, Luleå University of Technology, Luleå, SE-97187 Sweden

R. Larsson

Division of Machine Elements, Department of Engineering Science and Mathematics, Luleå University of Technology, Luleå, SE-97187 Sweden as introduced in previous work [3]. Furthermore a numerical simulation model is developed to investigate if there is a possibility that the hard, thin DLC coating is affecting the friction coefficient in an EHL contact due to thermal effects caused by the different thermal properties of the coating compared to the substrate. The experimental results show a reduction in friction coefficient in the full film regime when DLC coated surfaces are used. The biggest reduction is found when both surfaces are coated, followed by the case when either ball or disc is coated. The thermal simulation model shows a substantial increase of the lubricant film temperature compared to uncoated surfaces when both surfaces are coated with DLC. The reduction in friction coefficient when coating either only the ball or the disc are almost the same, lower than when coating both surfaces but still higher than the uncoated case. The findings above indicate that it is reasonable to conclude that thermal effects are a likely cause for the decrease in coefficient of friction when operating under full film conditions, and in the mixed lubrication regime when DLC coated surfaces are used.

Keywords diamond like carbon (DLC) · EHL . friction · coating $\cdot$ thermal effects $\cdot$ ball on disc

\section{Nomenclature}

$\delta_{t s} \quad$ Time scaling coefficient

$\epsilon \quad$ Thermal expansion coefficient $\left[{ }^{\circ} \mathrm{C}^{-1}\right]$

$\kappa \quad$ Thermal conductivity $[\mathrm{W} /(\mathrm{mK})]$

$\mu \quad$ Coefficient of friction

$\rho \quad$ Density $\left[\mathrm{kg} / \mathrm{m}^{3}\right]$

$B \quad$ Hertzian contact width $[\mathrm{m}]$

$c_{p} \quad$ Heat capacity at constant pressure $[\mathrm{J} /(\mathrm{kgK})]$

$h_{\text {cen }}$ Hamrock and Dowson central film thickness [m] 
$P_{h} \quad$ Hertzian pressure $[\mathrm{Pa}]$

$Q \quad$ Heat source $\left[\mathrm{W} / \mathrm{m}^{3}\right]$

$q \quad$ Invard heat flux $\left[\mathrm{W} / \mathrm{m}^{2}\right]$

$S \quad$ Slide to roll ratio

$S_{a} \quad$ Arithmetic average of absolute roughness [m]

$S_{q} \quad$ Root mean square roughness [m]

$S_{q c} \quad$ Root mean square combined roughness [m]

$T$ Temperature $\left[{ }^{\circ} \mathrm{C}\right]$

$t \quad$ Time $[\mathrm{s}]$

$T_{0} \quad$ Initial temperature $\left[{ }^{\circ} \mathrm{C}\right]$

$t_{c} \quad$ Contact time $[\mathrm{s}]$

$U_{b} \quad$ Surface velocity of ball $[\mathrm{m} / \mathrm{s}]$

$U_{d} \quad$ Surface velocity of disc $[\mathrm{m} / \mathrm{s}]$

$U_{e} \quad$ Entrainment speed $[\mathrm{m} / \mathrm{s}]$

$x \quad$ Cross film position $[\mathrm{m}]$

\section{Introduction}

The elasto hydrodynamic lubrication (EHL) performance of machine components is governed by many factors such as lubricant properties, load conditions, operating temperature, speed, slide to roll ratio and surface roughness. Increasing demands on improved efficiency, sustainability and longer service life have led to improvements in lubrication technology and surface finishing techniques as well as geometrical changes to components to improve the performance. In recent years tribological coatings have been more frequently used to improve the performance of machine components. The use of tribological coatings have been shown to have several benefits, such as improved running in performance, higher wear resistance and reduced friction. Some machine components like journal bearings are mainly operating in the full film regime, while other components like rolling contact bearings, gears and cam followers are operating in a range from boundary or mixed to full film EHL. It is therefore of interest to understand the influence of coatings in all regimes. The focus in this study is on thin, hard coatings usually deposited using physical vapor deposition (PVD) or plasma enhanced chemical vapour deposition (PECVD) such as different varieties of diamond like carbon (DLC). The following section contains a short review of the effect of DLC coatings on wear and above all friction in EHL contacts.

High hardness, high elastic modulus, low friction characteristics, high wear and corrosion resistance, chemical inertness and thermal stability are factors that make DLC coatings the subject of many studies, and seem suitable for use in, amongst others, machine components and cutting tools. DLC coatings show low dry friction (friction coefficients are typically in the range of 0.1-0.2) and wear rates compared to steel on steel in dry conditions, an effect mainly attributed to the formation of easily sheared graphitic layers on one or both of the mating surfaces [23,28]. It is reported that in some cases the friction coefficient of a steel-DLC dry interface is lower than a lubricated steel-steel interface [23]. However, most machine components are operating under lubricated conditions, and several studies have been conducted on the topic of DLC performance under lubricated conditions.

In general the friction in boundary lubrication is lower for a steel-DLC system compared to a steel-steel system and especially during the running in processes a system containing at least one DLC coated surface shows much lower initial friction coefficients, and a faster and more efficient running in $[23,20]$. A system where both surfaces are DLC coated also shows a lower initial friction value but a longer running in period as expected since both surfaces have high hardness and therefore need a longer time to smoothen down. Another issue that arises when both surfaces are coated are the surface additive interactions. Most of todays lubricants with extreme pressure (EP) and anti wear (AW) additives are formulated with steel contacts in mind, and when there is no steel surface available, the additives may not work as intended. Several studies indicate that EP and AW additives developed for steel-steel contacts still give beneficial effects in systems where two, or preferably one surface is coated with DLC [20, 21]. ZDDP has been widely used since 1960 and is proven to work well together with iron surfaces where a polyphosphate film is formed that gives good wear resistance. Podgornik et al. has found that a $W S_{2}$ tribofilm is formed when sulfur is present in the lubricant in a sliding WC DLC coating [19]. The same reaction was observed by Mistry et al. in tests run with WC DLC together with a lubricant containing ZDDP and MoDTC where $M o S_{2}$ and $W S_{2}$ tribofilms were formed resulting in promising friction and wear performance [16]. Several other authors have also studied the interaction between DLC coatings and the combination of ZDDP and MoDTC $[2,1,17,10,12]$. However depending on lubricant composition, additive package and type of DLC coating both friction and wear performance varies greatly so it is hard to draw any general conclusions [24, $27,22,13]$.

While most studies in literature focus on the influence of coatings on wear and friction in boundary lubrication and pure sliding contacts, few studies can be found concerning rolling and sliding EHL friction, especially in the mixed and full film regime. Renodeau et al. used a rolling sliding mini traction machine (MTM) to test discs coated with four different commercial DLC coatings against a steel ball with four different lubri- 
cants [22]. The entrainment speed in the test device was chosen to simulate mixed lubrication. Friction and wear of the different configurations were measured and showed dissimilar results, some material/lubricant combinations showed lower friction and wear compared to the steel-steel system whereas some combinations showed higher friction and wear. Topolovec-Miklozic et al. also performed tests in a MTM where two types of commercial DLC coatings were studied, one hydrogenated diamond like and the other Cr-doped, non hydrogenated and graphitic. The study focused on the effect of boundary friction with several types of additives [24]. Bobzin et al. performed tests in a twin disc tribometer with two different PVD coatings, WC/C and CrAIN, compared to uncoated discs [4]. Both of the latter studies report lower friction coefficients for the coated specimens in both boundary and mixed lubrication. It is however not clear if the friction reduction achieved in the mixed lubrication regime is solely attributed to lower friction in the asperity interactions or if there is also a beneficial effect in the hydrodynamic part of the mixed lubrication regime.

A dissertation written by Hai $\mathrm{Xu}$ at Ohio State university caught the authors interest [26]. Here tests were performed in a Wedeven Associates Machine (WAM) ball on disc test device with both uncoated and DLC coated steel balls and discs. The tested combinations were with either both ball and disc uncoated, or uncoated disc against a coated ball or both ball and disc coated. Results from the tests showed significantly reduced friction coefficients even in full film lubrication with coated surfaces, especially the case with both surfaces coated. Other than a comment that coatings should be considered in any efficiency improvement efforts there is no further discussions regarding how a coating can reduce friction in the full film regime. Evans et al. also performed tests in a WAM tribotester where discs with three different coatings were compared to an uncoated disc [6]. All discs were run against an uncoated steel ball. The tested coatings were chromium nitride $\left(\mathrm{C} r_{x} \mathrm{~N}\right)$, tungsten carbide-reinforced amorphous hydrocarbon (WC/a-C:H) and silicon incorporated diamond like carbon (Si-DLC). At lower entrainment speeds where the asperity interaction between the mating surfaces are large the $\mathrm{C} r_{x} \mathrm{~N}$ coating had the highest friction whereas the WC/a-C:H and especially Si-DLC showed lower friction than the uncoated surface. At higher entrainment speeds where full film lubrication was assumed the Si-DLC and WC/a-C:H showed lower friction coefficients than the uncoated surface. The reason for this is hypothesized to be due to boundary slip between smooth, non wetting surfaces as addressed by Choo et al. [5]. An interfacial slip would lead to lower shear stresses and thus lower friction in the EHL contact. In the work presented by Evans et al. low surface energy is correlated with low friction as the Si-DLC coating that has lower surface energy compared to WC/a-C:H showed even lower friction in the full film regime.

The authors have not found any studies in the literature focusing on the effect of DLC coatings on the friction coefficient in the full film EHL regime, especially addressing the effect of coating both surfaces or the combination of coating either ball or disc. Is it reasonable that boundary slip is the reason for the reduction in friction coefficient, or is there possibly other reasons as well?

In the present paper tests are carried out in a WAM tribotester where an uncoated ball and disc pair is compared to the case of coated ball against uncoated disc, coated disc against uncoated ball, and coated disc against coated ball. The tests are conducted at two different temperatures and over a broad range of slide to roll ratios and entrainment speeds. The results are presented as friction maps as introduced in previous work [3]. Furthermore a numerical simulation model is developed to investigate if there is a possibility that the hard thin DLC coating is affecting the friction coefficient in an EHL contact due to thermal effects caused by the different thermal properties of the coating compared to the substrate.

\section{Method}

The following sections cover a description of the ball on disc test rig, the test specimens and lubricant, and an overview of the test procedure. Furthermore the numerical simulation model is described together with boundary conditions and assumptions.

\subsection{Ball on disc tribotester}

The experiments were performed in a WAM 11 ball on disc test device as shown in Figure 1. The lubricant is supplied at the centre of the disc in an oil dispenser that distributes the lubricant across the disc surface. Lubricant is circulated in a closed loop from the oil bath, through a hose pump to the oil dispenser at the centre of the disc. The hose pump is delivering approximately $140 \mathrm{ml} / \mathrm{min}$. Three thermocouples are used in the test setup, one located in the oil bath, one in the outlet of the oil supply and one trailing in the oil film close to the inlet region of the ball on disc contact. A more thorough description of the test rig and its features is presented in previous work [3]. 


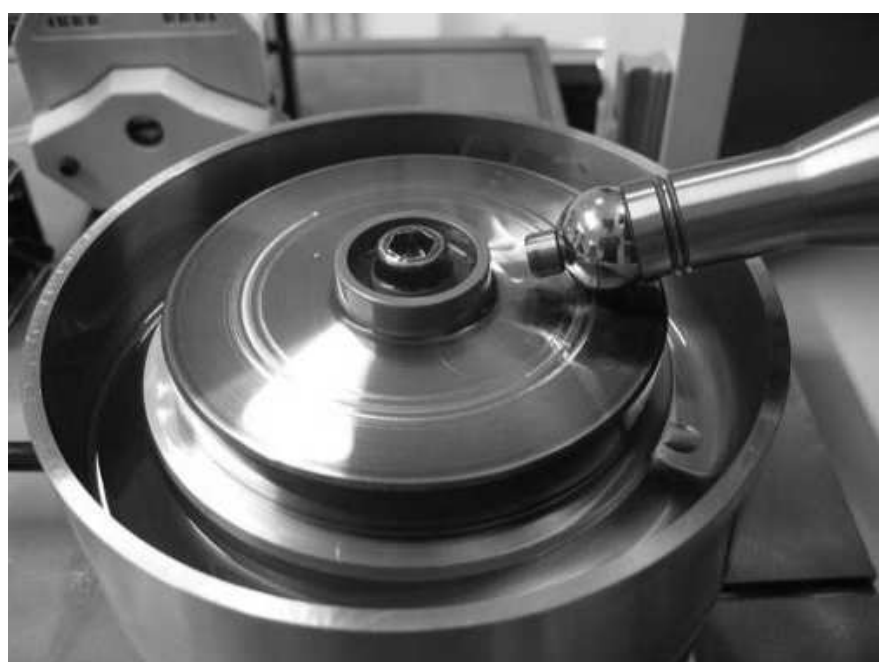

Fig. 1 WAM ball on disc test device

Table 1 Test lubricant properties

\begin{tabular}{lc}
\hline Additives & None \\
Kin. Visc @ $40^{\circ} \mathrm{C}$ & $109.3 \mathrm{cSt}$ \\
Dyn. Visc @ $40^{\circ} \mathrm{C}$ & $94.9 \mathrm{mPas}$ \\
Kin. Visc @ $100^{\circ} \mathrm{C}$ & $11.98 \mathrm{cSt}$ \\
Dyn. Visc @ $100^{\circ} \mathrm{C}$ & $9.97 \mathrm{mPas}$ \\
Density @ $15^{\circ} \mathrm{C}$ & $885 \mathrm{~kg} / \mathrm{m}^{3}$ \\
Viscosity Index & 99 \\
Type & $\mathrm{Mineral}$ \\
Thermal conductivity & $0.3 \mathrm{~W} / \mathrm{mK}$ \\
Heat capacity & $1800 \mathrm{~J} / \mathrm{kgK}$ \\
Pressure viscosity coefficient & $19 \mathrm{GPa}^{-1}$ \\
Temperature viscosity coefficient & $0.04 \mathrm{~K}^{-1}$ \\
Thermal expansion coefficient & $6.5 \mathrm{e}-4^{\circ} \mathrm{C}^{-1}[15]$ \\
\hline
\end{tabular}

\subsection{Test specimens and lubricants}

All tests were performed with the same lubricant, a pure mineral oil without any additives. An oil without additives was chosen to minimize the effect of tribochemical reactions on the friction coefficient. As explained later the tests are conducted repeatedly until a satisfactory repeatability is reached, and since this could take a different amount of cycles for different test cases a lubricant containing additives could be in different stages of tribofilm development. Properties of the test lubricant are given in Table 1.

All specimens used in the tests, both balls and discs are made from AISI 52100 bearing steel, where the balls are taken direct from factory and the discs are processed the same way as bearing raceway material. The balls are grade 20 with a 13/16 inch $(20.637 \mathrm{~mm})$ outer diameter and a hardness of about $60 \mathrm{HRC}$. The discs have a 4 inch $(101.6 \mathrm{~mm})$ outer diameter, a circumferential grind and are through hardened to about $60 \mathrm{HRC}$.

The commercially available coating Tribobond 44 was used on all coated specimens. Tribobond 44 is an a-C:Cr coating deposited using reactive PVD processes with a deposition temperature of $200^{\circ} \mathrm{C}$. The thickness of the coatings are $2 \mu \mathrm{m}$, the hardness $1500 H V_{0.005}$ and the friction coefficient against steel in dry sliding is 0.08. Both balls and discs were measured for surface roughness data before and after friction testing with a Wyko NT1100 optical profilometer system from Veeco. Measurements were performed using 10x magnification and $1 \mathrm{x}$ field of view (FOV). Twenty one measurements were made per ball, seven on the unworn surface, and seven in each wear track after testing. The discs were measured in several positions, and for each radius thirteen measurements were made. For each series of measurements mean values and standard deviations are calculated for the root mean square roughness, $S_{q}$ and the arithmetic average of absolute roughness, $S_{a}$.

\subsection{Test procedure}

The WAM is used to generate friction data from a relatively broad range of operating conditions where one test cycle covers entrainment speeds between 0.34 to 9.6 $\mathrm{m} / \mathrm{s}$ and slide to roll ratios (SRR) from 0.0002 to 0.49 . $\mathrm{SRR}$ is defined as the speed difference divided by the mean entrainment speed. All test are performed with positive sliding only, which in this case means that the ball is rotating faster than the disc. Both ball and disc specimens were cleaned with heptane and ethyl alcohol before starting the experiments for each of the test cases. Before starting the experiments for each test case the test device is warmed up to the desired operation temperature during approximately 60 minutes with oil circulation over both ball and disc to ensure temperature stability. When thermal stability is reached a 200 $\mathrm{N}$ load, equivalent to $1.7 \mathrm{GPa}$ maximum Hertzian pressure is applied and the machine is calibrated for pure rolling by adjusting spindle angle and positioning of the ball to ensure a condition of no spinning. These settings are then held constant for 20 minutes to ensure a mild run-in. Subsequently the test cycle is started that contains several loops where SRR is held constant for each loop and the entrainment speed is ramped from 9.6 to $0.34 \mathrm{~m} / \mathrm{s}$. In the first loop the SRR is held at 0.0002 and is continously increased with each loop until it reaches 0.49. The same test cycle is repeated in the same track for both ball and disc until the absolute friction coefficient for each measured combination of entrainment speed and SRR does not differ more than 0.001 from the previous test cycle, excluding SRR below 0.0016 where the accuracy of the machine is slightly lower. When this occurs, the system is considered run in, and the data from the final test cycle is used for evaluation. The temperature of the oil bulk and fluid film at the disc surface is typically deviating less than $\pm 1.5^{\circ} \mathrm{C}$ from the target temperatures of 40 and $90{ }^{\circ} \mathrm{C}$ during testing. The 
actual contact temperatures are however higher than the bulk oil temperature. In the most severe cases with high entrainment speed, SRR and coefficient of friction $(\mathrm{COF})$, the contact temperature will increase several tens of degrees [7].

Data from each test is processed separately, and a triangle based linear interpolation is used between the data points measured for specific SRR's and entrainment speeds. The results are presented as $2 \mathrm{D}$ contour maps.

\subsection{Simulation model}

To investigate if there is a possibility that a hard thin DLC coating is affecting the friction coefficient in a EHL contact due to thermal effects caused by the different thermal properties of the coating compared to the substrate a numerical simulation model is developed. While bulk DLC can have very high thermal conductivity it is shown by several authors that thin DLC films can become insulating due to interfacial effects $[14,25]$. A one dimensional model is developed that features a thin oil film between two infinitely wide and flat, full film lubricated surfaces, with or without coatings subjected to a heat source. The solution is time dependent where the temperature rise in a line directed in the cross section of the film thickness passing the centre of the contact from leading edge to trailing edge is calculated. In that way the temperature distribution in a plane crossing the centre of the contact is obtained. The time it takes for the line to move from the leading edge to the trailing edge is calculated by dividing the Hertzian contact zone with the surface velocity of the faster moving surface:

$t_{c}=B / U_{b}$

where

$$
\begin{aligned}
& t_{c}=\text { Contact time }[\mathrm{s}] \\
& \mathrm{B}=\text { Hertzian contact width }[\mathrm{m}] \\
& U_{b}=\text { Surface velocity of ball }[\mathrm{m} / \mathrm{s}]
\end{aligned}
$$

The dimensions of the contact zone is approximated by the Hertzian theory using the 52100 steel values for elastic modulus and Poisson's ratio. Since the coatings are thin the substrate is assumed to predominate the EHL deformation in the contact. Since the authors did not have the possibility to perform thermal measurements on the DLC coating used in this study the thermal properties are collected from work performed by other authors $[14,25,8,18]$. Properties of the DLC coating and substrate used in the model are given in Table 2 , the oil properties in Table 1 and a schematic view of the model in Figure 2. Numbers 1-6 in Figure 2 corresponds to boundary points, and the letters A-E are computational domains where the heat equation is being solved. The heat equation solved in the domains A-E is expressed as:

$\delta_{t s} c_{p} \rho \frac{\partial T}{\partial t}+\nabla(-\kappa \nabla T)=Q$

where

$\delta_{t s}=$ Time scaling coefficient

$\rho=$ Density $\left[\mathrm{kg} / \mathrm{m}^{3}\right]$

$c_{p}=$ Heat capacity at constant pressure $[\mathrm{J} /(\mathrm{kgK})]$

$\kappa=$ Thermal conductivity $[\mathrm{W} /(\mathrm{mK})]$

$\mathrm{Q}=$ Heat source $\left[\mathrm{W} / \mathrm{m}^{3}\right]$

$\mathrm{T}=$ Temperature $\left[{ }^{\circ} \mathrm{C}\right]$

$\mathrm{t}=$ Time $[\mathrm{s}]$

The energy input of the heat source that is applied uniformly throughout the lubricant film is calculated as:

$Q=\mu P_{h} \frac{S U_{e}}{h_{c e n}}+\epsilon T \frac{\partial P_{h}}{\partial t}$

where

$$
\begin{aligned}
& P_{h}=\text { Hertzian pressure }[\mathrm{Pa}] \\
& \mu=\text { Coefficient of friction } \\
& \mathrm{S}=\text { Slide to roll ratio } \\
& U_{e}=\text { Entrainment speed }[\mathrm{m} / \mathrm{s}] \\
& h_{c e n}=\text { Central film thickness }[\mathrm{m}] \\
& \epsilon=\text { Thermal expansion coefficient }\left[{ }^{\circ} C^{-1}\right]
\end{aligned}
$$

The surfaces will be in contact with the oil film under different amounts of time, since the surface speed of the ball and disc are different due to sliding. The simulation time is governed by the time it takes for the faster sliding ball to pass the Hertzian contact width of the ball-on-disc contact, and a time scaling coefficient is therefore applied on the slower moving surface of the disc, both in case of coated or uncoated. The time scaling coefficient for the disc is given as:

$\delta_{t s}=\frac{U_{d}}{U_{b}}$

where

$$
\begin{aligned}
& U_{d}=\text { surface velocity of disc }[\mathrm{m} / \mathrm{s}] \\
& U_{b}=\text { surface velocity of ball }[\mathrm{m} / \mathrm{s}]
\end{aligned}
$$

For the same reason a time scaling coefficient is also applied on the lubricant film, but instead of being constant it is a function of the position, $x$ across the film:

$\delta_{t s}=\frac{U_{d}}{U_{b}}+\frac{1-\frac{U_{d}}{U_{b}}}{h_{c e n}} x$ 


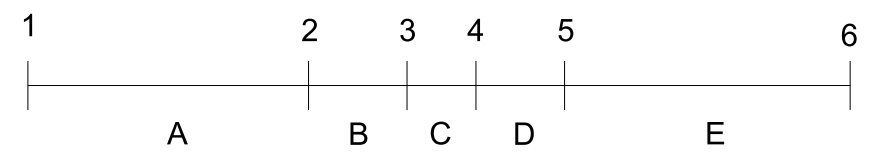

Fig. 2 Schematic view of thermal model, not to scale

Table 2 Model properties

\begin{tabular}{lcc}
\hline & DLC & AISI 52100 \\
\hline Density [kg/m ${ }^{3}$ ] & 2500 & 7810 \\
Thermal conductivity [W/mK] & 2 & 46.6 \\
Heat capacity [J/kgK] & 1000 & 475 \\
Elastic modulus [GPa] & & 210 \\
Poisson's ratio & & 0.3 \\
\hline
\end{tabular}

For all other domains the time scaling coefficient is set to 1. The steel surfaces that are domains $\mathrm{A}$ and $\mathrm{E}$ in Figure 2 are assigned the thickness of the disc and the diameter of the ball, and the coatings, that are assigned domains B and D have a fixed thickness set to $2 \mu \mathrm{m}$. The oil film is assigned domain $\mathrm{C}$ and the thickness is approximated by the Hamrock-Dowson equation for central film thickness [9] and a thermal correction model developed by Hsu and Lee [11] is used to compensate for thermal thinning of the lubricant film. The outer boundaries of the steel surfaces, points 1 and 6 , are assigned the bulk oil temperature, and the interior boundaries 2-5 are assigned a continuity condition.

Therefore the boundary conditions can be described as:

Boundary 1 and $6: \mathrm{T}=\mathrm{T}_{0}$

Internal boundaries $i=2-5:\left.\mathrm{k}_{i} \nabla T_{i}\right|_{-}=\left.\mathrm{k}_{i} \nabla T_{i}\right|_{+}$and $\left.T_{i}\right|_{-}=\left.T_{i}\right|_{+}$

where $T_{0}$ is the initial temperature. All subdomains are assigned the bulk oil temperature as an initial value $\left(\mathrm{T}_{0}\right)$ :

For A-E: $\mathrm{T}\left(\mathrm{t}_{0}\right)=\mathrm{T}_{0}$

All solutions are checked for convergence with respect to both mesh size and time step length.

\section{Results and discussion}

Eight different combinations were evaluated as presented in Table 3. Depending on surface roughness, coatings and operating temperature a different amount of test cycles were required to meet the criterion of running in, as listed in Table 3. Table 3 also contains information about the root mean square combined roughness, $S_{q c}$ of each test combination measured after the test
Table 3 Test combinations

\begin{tabular}{lccccc}
\hline Case & Ball & Disc & Temp & Cycles & $S_{q c}[\mathrm{~nm}]$ \\
\hline 1 & Uncoated & Uncoated & $40{ }^{\circ} \mathrm{C}$ & 4 & 155 \\
2 & Uncoated & Uncoated & $90{ }^{\circ} \mathrm{C}$ & 11 & 157 \\
3 & Uncoated & Coated & $40{ }^{\circ} \mathrm{C}$ & 4 & 355 \\
4 & Uncoated & Coated & $90{ }^{\circ} \mathrm{C}$ & 11 & 293 \\
5 & Coated & Uncoated & $40{ }^{\circ} \mathrm{C}$ & 4 & 170 \\
6 & Coated & Uncoated & $90{ }^{\circ} \mathrm{C}$ & 11 & 162 \\
7 & Coated & Coated & $40{ }^{\circ} \mathrm{C}$ & 4 & 315 \\
8 & Coated & Coated & $90{ }^{\circ} \mathrm{C}$ & 11 & 259 \\
\hline
\end{tabular}

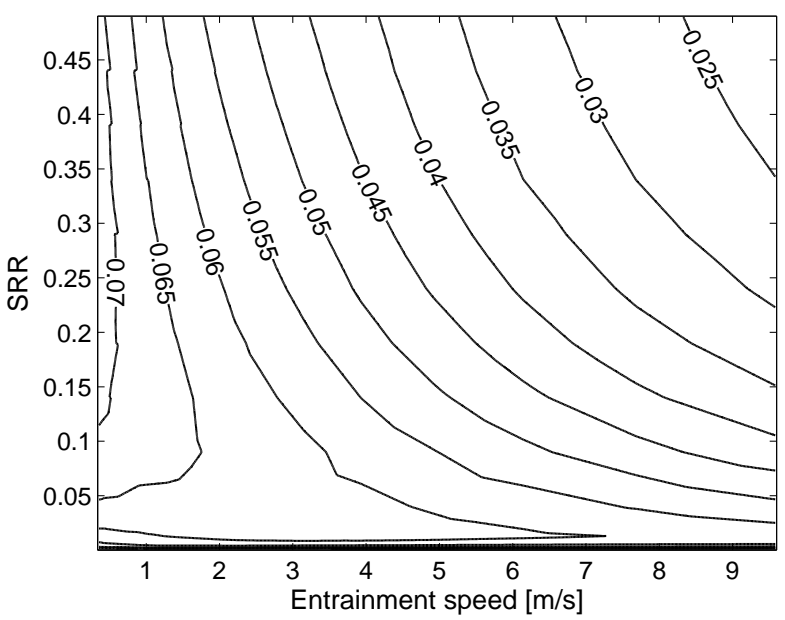

Fig. 3 Uncoated disc against uncoated ball at $40^{\circ} \mathrm{C}$

has been completed. Table 4 contains information from the surface roughness measurements made on the ball and disc specimens before and after testing. The measurements show that the uncoated balls wear more than the coated ones regardless of if the counter surface is coated or not.

Case one and two where an uncoated ball is run against an uncoated disc at 40 and $90{ }^{\circ} \mathrm{C}$ are considered as reference cases, and are shown in Figs. 3 and 4. The results are presented as $2 \mathrm{D}$ friction maps whose advantages and features are described in detail elsewhere [3] where the friction coefficient is plotted against SRR and entrainment speed. Similar 2D maps are obtained for case 3-8, but are not shown here. Instead the absolute coefficients of friction from case 3,5 and 7 that are conducted with a lubricant bulk temperature of $40{ }^{\circ} \mathrm{C}$ are subtracted from case 1 and displayed as difference maps in Figs. 5-7. In these figures a positive number indicates that the presented case had a lower coefficient of friction $(\mathrm{COF})$ compared to the reference case, and vice versa for negative numbers. The results from case 4, 6 and 8 that are conducted with a bulk temperature of $90{ }^{\circ} \mathrm{C}$ are in the same way subtracted from case 2 and shown in Figs. 8-10.

As seen in Figs. 5-7 the friction coefficients at higher entrainment speeds when full film lubrication is assumed to occur are generally lower when one or both surfaces 
Table 4 Surface roughness measurements for ball and disc specimens

\begin{tabular}{lcccccc}
\hline Ball & $\begin{array}{c}\text { Counter } \\
\text { surface }\end{array}$ & $\begin{array}{c}\text { Temp } \\
{\left[{ }^{\circ} \mathrm{C}\right]}\end{array}$ & $\begin{array}{c}S_{a} \\
{[\mathrm{~nm}]}\end{array}$ & $\begin{array}{c}S_{q} \\
{[\mathrm{~nm}]}\end{array}$ & $\begin{array}{c}\text { Std } S_{a} \\
{[\mathrm{~nm}]}\end{array}$ & $\begin{array}{c}\text { Std } S_{q} \\
{[\mathrm{~nm}]}\end{array}$ \\
\hline Coated* & - & - & 25 & 41 & 3 & 8 \\
Coated & Uncoated & 40 & 33 & 54 & 2 & 6 \\
Coated & Uncoated & 90 & 31 & 54 & 1 & 5 \\
Coated* & - & - & 31 & 53 & 4 & 11 \\
Coated & Coated & 40 & 41 & 72 & 4 & 9 \\
Coated & Coated & 90 & 29 & 51 & 2 & 13 \\
Uncoated* & - & - & 35 & 53 & 4 & 8 \\
Uncoated & Uncoated & 40 & 47 & 78 & 4 & 13 \\
Uncoated & Uncoated & 90 & 70 & 124 & 5 & 6 \\
Uncoated $*$ & - & - & 32 & 47 & 2 & 6 \\
Uncoated & Coated & 40 & 88 & 133 & 10 & 12 \\
Uncoated & Coated & 90 & 64 & 90 & 8 & 13 \\
& & & & & & \\
\hline Disc & Counter & Temp & $S_{a}$ & $S_{q}$ & Std $S_{a}$ & Std $S_{q}$ \\
& surface & {$\left[{ }^{\circ} \mathrm{C}\right]$} & {$[\mathrm{nm}]$} & {$[\mathrm{nm}]$} & {$[\mathrm{nm}]$} & {$[\mathrm{nm}]$} \\
\hline Coated* & - & - & 215 & 270 & 22 & 25 \\
Coated & Coated & 40 & 244 & 303 & 32 & 39 \\
Coated & Coated & 90 & 203 & 254 & 31 & 36 \\
Coated & Uncoated & 40 & 267 & 329 & 16 & 18 \\
Coated & Uncoated & 90 & 224 & 279 & 39 & 46 \\
Uncoated $*$ & - & - & 110 & 144 & 7 & 9 \\
Uncoated & Coated & 40 & 246 & 309 & 19 & 27 \\
Uncoated & Coated & 90 & 206 & 260 & 17 & 20 \\
Uncoated & Uncoated & 40 & 201 & 134 & 4 & 5 \\
Uncoated & Uncoated & 90 & 108 & 140 & 5 & 6 \\
\hline * Unworn & & & & & & 5
\end{tabular}

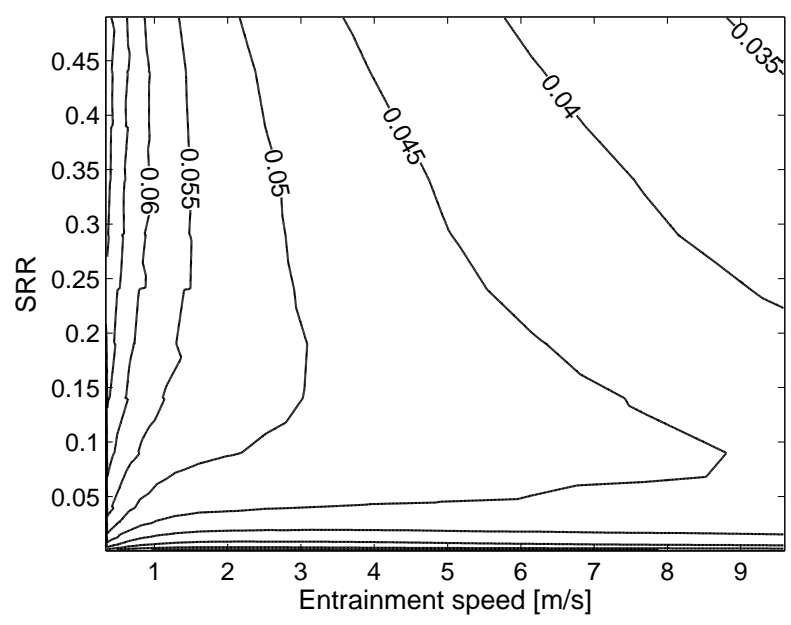

Fig. 4 Uncoated disc against uncoated ball at $90^{\circ} \mathrm{C}$

are coated with DLC, which is consistent with earlier findings $[26,6]$. The biggest decrease in friction coefficient is achieved when both surfaces are coated, as also reported elsewhere [26], followed by coating only the disc, and then the smallest reduction by only coating the ball. However, at lower speeds where mixed lubrication is assumed to occur the friction coefficients are higher for all coated cases. The reason for this is probably due to the rougher surface of the DLC coated disc that promotes a transition to mixed lubrication from full film lubrication at higher entrainment speeds.

The same trend can be seen in Figs 8-10 where the increased oil bulk temperature from 40 to $90^{\circ} \mathrm{C}$ leads to a thinner lubricant film and thus promotes a tran- sition to mixed lubrication at even higher entrainment speeds compared to the lower temperature, especially in the cases when the rougher DLC coated discs are used. With increasing entrainment speed and especially SRR the combinations with one or two surfaces coated with DLC will show COF lower than the reference case. This is mainly believed to be due to lower hydrodynamic friction, as seen in the low temperature case, but possibly also due to a lower COF in the asperity interactions compared to steel against steel. The difference between figures 8 and 10 is therefore most likely to be explained by the reduction in hydrodynamic friction by coating both surfaces rather than one, and also the slightly lower combined roughness in the DLC-DLC combination. In Figure 9 where only the ball is DLC coated there seem to be no substantial differences compared to the reference case, indicating that the friction coefficient between steel-steel asperities and steel-DLC asperities in this case is roughly the same.

It is evident that the DLC coating in some way promotes lower friction coefficients compared to the uncoated references cases, in these tests most noticeably in the full film regime. Choo et al. [5] have discussed that smooth surfaces are one of the key factors for the boundary slip theory. They tested coated surfaces with RMS roughness of 0.75 and $9.5 \mathrm{~nm}$ and found negligible difference in friction between the rough $(9.5 \mathrm{~nm})$ coated surface and an uncoated surface with roughness of the same magnitude, while the smoother surface showed a significant reduction in friction compared to its uncoated counterpart. Considering that the coated surfaces used in this study are one or two orders of magnitude larger than the rough surfaces used by Choo et al. it is likely that boundary slip is not the dominant reason, or possibly not part at all in the decrease in friction coefficient found with the coated surfaces in this study.

Part of the explanation may be found from the thermal simulation model. Figure 11 shows a graph of the maximum value of the mean cross film temperature increase in the lubricant as the computational domain passes the contact zone. Values are presented for four different combinations of entrainment speeds and SRR. The simulation has been run for both the reference case with uncoated surfaces, but also with the other cases with one or both surfaces coated. All simulations has been performed with an initial temperature of $40^{\circ} \mathrm{C}$ since the experiments conducted at $90^{\circ} \mathrm{C}$ indicates mixed lubrication in large parts of the tested operating range.

There is a significant increase in temperature for all cases where one or both surfaces are coated with DLC. The highest temperature increase is found for the case when both surfaces are coated with DLC followed by 


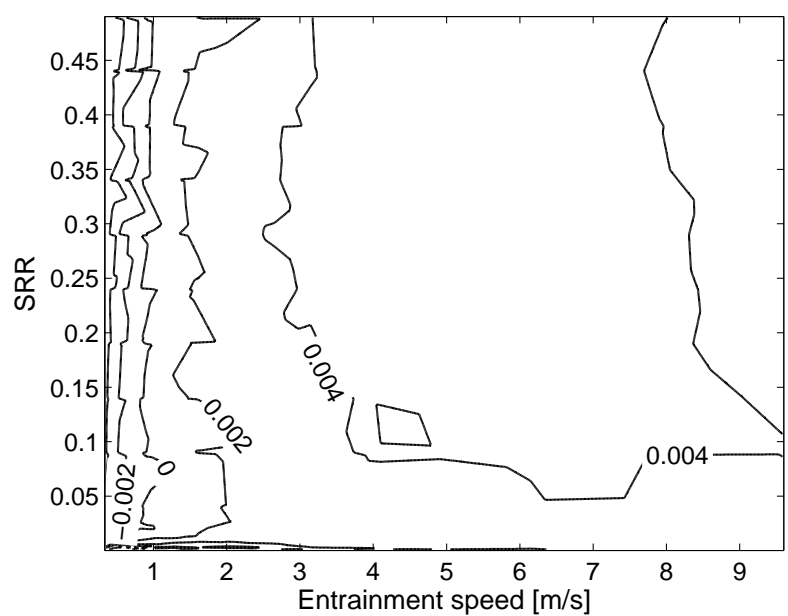

Fig. 5 Difference in friction coefficients between case 1 and 3 , uncoated references compared to uncoated ball and DLC coated disc @ $40^{\circ} \mathrm{C}$

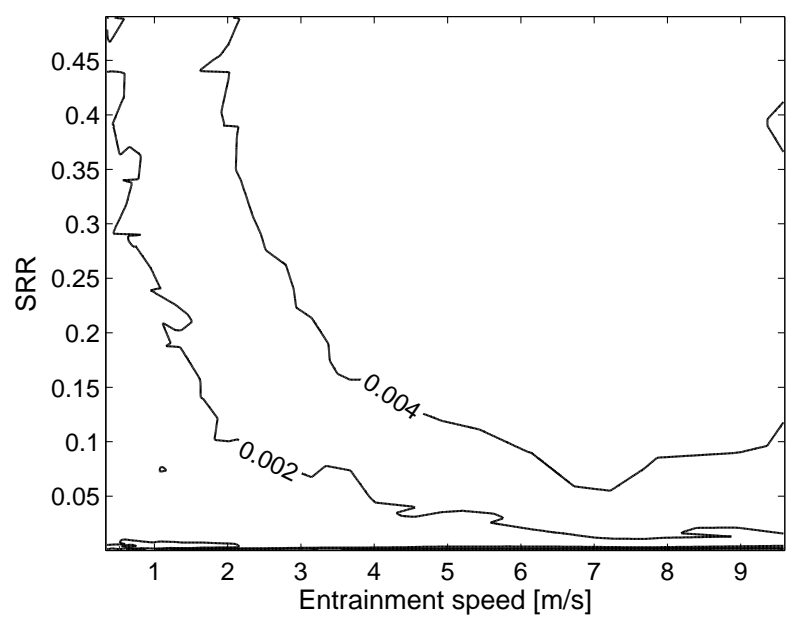

Fig. 6 Difference in friction coefficients between case 1 and 5 , uncoated references compared to DLC coated ball and uncoated disc @ $40^{\circ} \mathrm{C}$

the case where the ball is coated with DLC and the disc is uncoated. These findings are in line with the experimental results that showed the biggest decrease in $\mathrm{COF}$ for the cases where both surfaces were coated with DLC, and only a negligible difference between coating the ball, or the disc, but still a substantial difference compared to having both ball and disc uncoated. An increased temperature in the contact leads to lower shear resistance and lower limiting shear strength and it is therefore likely that it will result in lower friction coefficients. An increased temperature in the contact will only have a small effect on film thickness since the lubricant film build-up is mainly governed by the viscosity in the inlet region of the contact, which is not subjected to the same temperature increase as the lu-

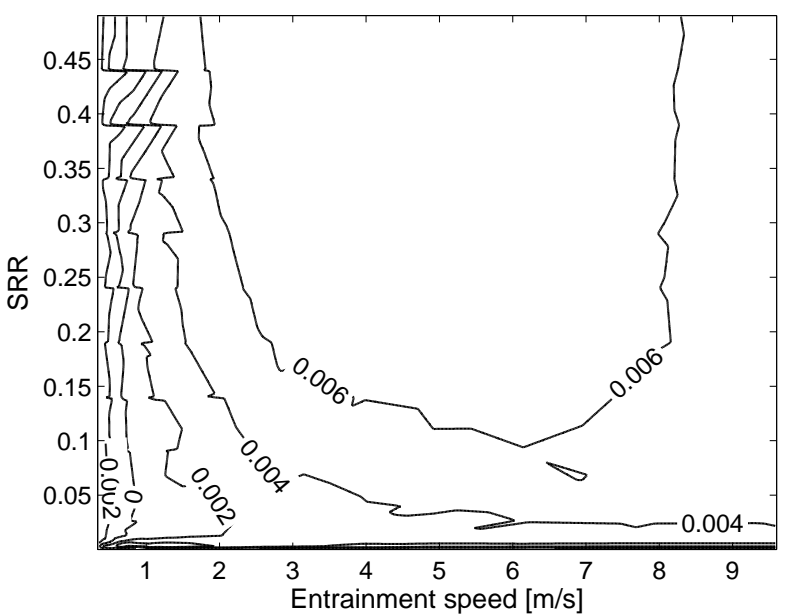

Fig. 7 Difference in friction coefficients between case 1 and 7 , uncoated references compared to DLC coated ball and DLC coated disc @ $40^{\circ} \mathrm{C}$

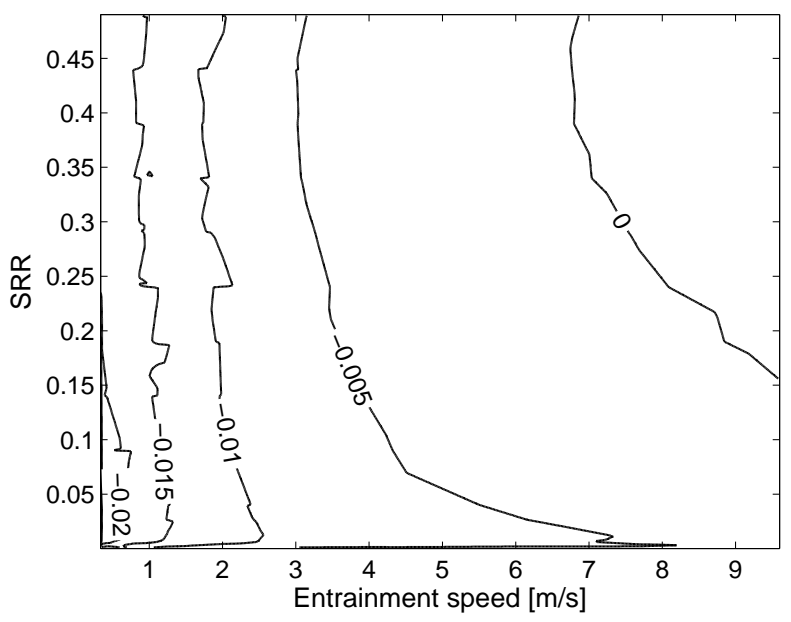

Fig. 8 Difference in friction coefficients between case 2 and 4 , uncoated references compared to uncoated ball and DLC coated disc @ $90^{\circ} \mathrm{C}$

bricant inside the contact. It is reasonable to believe that thermal effects are most likely to be one of the reasons for the decrease in coefficient of friction seen in the experiments. Especially at higher SRR the temperature increase is substantial. However, at lower SRR the increase in temperature is not as distinct, and even though the experiments show less decrease in COF at lower SRR it is possible that there are other effects as well that are part of the reduction in COF. One possibility is the fact that the thermal model does not take global effects into account, and there could also be other factors. 


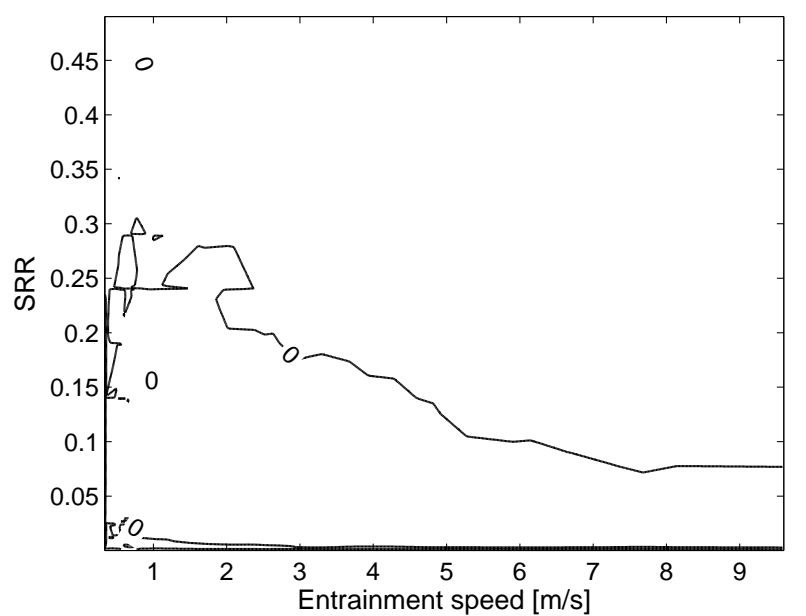

Fig. 9 Difference in friction coefficients between case 2 and 6 , uncoated references compared to DLC coated ball and uncoated disc @ $90^{\circ} \mathrm{C}$

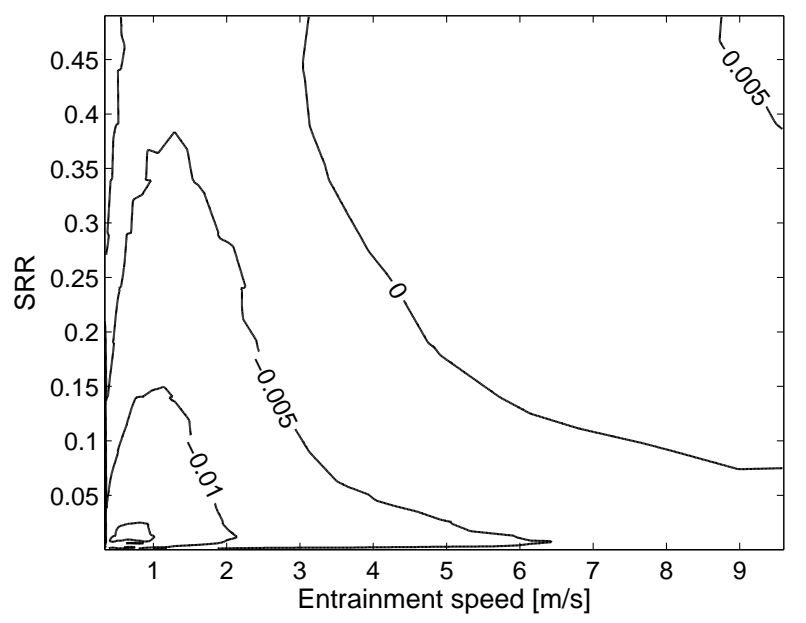

Fig. 10 Difference in friction coefficients between case 2 and 8, uncoated references compared to DLC coated ball and DLC coated disc @ $90^{\circ} \mathrm{C}$

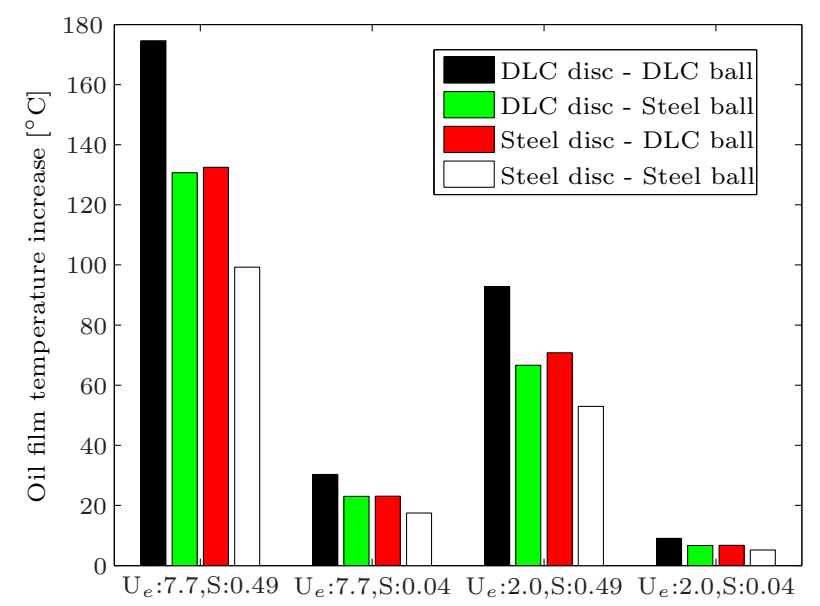

Fig. 11 Simulated temperature increase in lubricant

\section{Conclusions}

The experiments conducted in the ball on disc apparatus with both coated and uncoated specimens show that:

- There is a reduction in coefficient of friction in the full film regime when a DLC coating is applied to at least one of the surfaces.

- The biggest reduction in coefficient of friction is found when both ball and disc are coated.

- There is only a very small difference in coefficient of friction comparing coating only the ball, or only the disc.

- The decrease in coefficient of friction is generally increasing with entrainment speed, and especially SRR.

The thermal simulation model shows that:

- The increase of the lubricant film temperature is largest compared to uncoated surfaces when both surfaces are coated with DLC. The reduction in friction coefficient when coating only the ball, or only the disc are almost the same, lower than coating both surfaces but still higher than the uncoated case.

- The increase of mean lubricant film temperature is larger for higher entrainment speeds, and above all for higher SRR.

The findings above indicate that it is reasonable to conclude that thermal effects are a likely cause for the decrease in coefficient of friction in the full film, and mixed lubrication regime when DLC coated surfaces are used.

Acknowledgements The authors gratefully acknowledge industrial partners Volvo Construction Equipment, Scania and Vicura AB for support, Ion Bond for providing the coatings, Statoil lubricants for providing the test lubricant, and Swedish Foundation for Strategic Research (ProViking) for financial support.

\section{References}

1. de Barros'Bochet, M., Martin, J., Le-Mogne, T., Vacher, B.: Boundary lubrication mechanisms of carbon coatings by MoDTC and ZDDP additives. Tribology International 38(3), 257-264 (2005). DOI 10.1016/j.triboint.2004.08.009

2. de Barros'Bochet, M., Martin, J., Le-Mogne, T., Vacher, B.: Lubrication of carbon coatings with MoS2 single sheet formed by MoDTC and ZDDP lubricants. Lubrication Science 18(3), 141-149 (2006). DOI 10.1002/ls.13

3. Björling, M., Larsson, R., Marklund, P., Kassfeldt, E.: Elastohydrodynamic lubrication friction mapping - the influence of lubricant, roughness, speed, and slide-to-roll 
ratio. Proceedings of the Institution of Mechanical Engineers, Part J: Journal of Engineering Tribology 225(7), 671-681 (2011). DOI 10.1177/1350650111403363

4. Bobzin, K., Bagcivan, N., Goebbels, N., Yilmaz, K., Hoehn, B.R., Michaelis, K., Hochmann, M.: Lubricated PVD CrAlN and WC/C coatings for automotive applications. Surface and Coatings Technology 204(6-7), 10971101 (2009). DOI 10.1016/j.surfcoat.2009.07.045

5. Choo, J., Glovnea, R., Forrest, A., Spikes, H.: A low friction bearing based on liquid slip at the wall. Journal of Tribology 129(3), 611-620 (2007). DOI $10.1115 / 1.2736704$

6. Evans, R., Cogdell, J., Richter, G.: Traction of lubricated rolling contacts between thin-film coatings and steel. Tribology Transactions 52(1), 106-113 (2009). DOI 10.1080/10402000802180144

7. Habchi, W., Eyheramendy, D., Bair, S., Vergne, P., Morales-Espejel, G.: Thermal elastohydrodynamic lubrication of point contacts using a newtonian/generalized newtonian lubricant. Tribology letters $\mathbf{3 0}(\mathbf{1}), 41-52$ (2008). DOI $10.1007 / \mathrm{s} 11249-008-9310-9$

8. Hakovirta, M., Vuorinen, J., He, X., Nastasi, M., Schwarz, R.: Heat capacity of hydrogenated diamond-like carbon films. Applied Physics Letters 77/15), 2340-2342 (2000). DOI 10.1063/1.1290387

9. Hamrock, B., Schmid, S., Jacobson, B.: Fundamentals of fluid film lubrication - SE. Marcel Dekker, Inc (2004)

10. Haque, T., Morina, A., Neville, A., Kapadia, R., Arrowsmith, S.: Effect of oil additives on the durability of hydrogenated DLC coating under boundary lubrication conditions. Wear 266(1-2), 147-157 (2009). DOI 10.1016/j.wear.2008.06.011

11. Hsu, C.H., Lee, R.T.: An efficient algorithm for thermal elastohydrodynamic lubrication under rolling/sliding line contacts. Journal of tribology 116(4), 762-769 (1994). DOI $10.1115 / 1.2927330$

12. Kalin, M., Roman, E., Obolt, L., Viintin, J.: Metaldoped ( $\mathrm{Ti}, \mathrm{WC}$ ) diamond-like-carbon coatings: Reactions with extreme-pressure oil additives under tribological and static conditions. Thin solid films 518(15), 43364344 (2010). DOI 10.1016/j.tsf.2010.02.066

13. Kalin, M., Viintin, J.: Differences in the tribological mechanisms when using non-doped, metal-doped (Ti, $\mathrm{WC}$ ), and non-metal-doped (Si) diamond-like carbon against steel under boundary lubrication, with and without oil additives. Thin solid films 515(4), 2734-2747 (2006). DOI 10.1016/j.tsf.2006.03.034

14. Kim, J., Yang, H.S., Jun, Y., Kim, K.: Interfacial effect on thermal conductivity of diamond-like carbon films. Journal of Mechanical Science and Technology 24(7), 15111514 (2010). DOI 10.1007/s12206-010-0416-2

15. Larsson, R., Larsson, P., Eriksson, E., Sjoberg, M., Hoglund, E.: Lubricant properties for input to hydrodynamic and elastohydrodynamic lubrication analyses. Proceedings of the Institution of Mechanical Engineers, Part J: Journal of Engineering Tribology 214(1), 17-27 (2000)

16. Mistry, K., Morina, A., Neville, A.: Tribo-chemistry of lubricated DLC coatings for engineering components under extreme-pressure contact conditions. Tribology and Lubrication Technology 66(5), 16-17 (2010)

17. Miyake, S., Saito, T., Yasuda, Y., Okamato, Y., Kano, M.: Improvement of boundary lubrication properties of diamond-like carbon (DLC) films due to metal addition. Tribology International 37 (9), 751-761 (2004). DOI 10.1016/j.triboint.2004.01.014
18. Oka, Y., Kirinuki, M., Suzuki, T., Yatsuzuka, M., Yatsui, K.: Effect of ion beam implantation on density of DLC prepared by plasma-based ion implantation and deposition. Nuclear Instruments and Methods in Physics Research, Section B: Beam Interactions with Materials and Atoms 242(1-2), 335-357 (2006). DOI 10.1016/j.nimb.2005.08.203

19. Podgornik, B., D.Hren, Viintin, J.: Combination of DLC coatings and EP additives for improved tribological behaviour of boundary lubricated surfaces. Wear 261(1), 32-40 (2006). DOI doi:10.1016/j.wear.2005.09.007

20. Podgornik, B., Jacobson, S., Hogmark, S.: DLC coating of boundary lubricated components - advantages of coating one of the contact surfaces rather than both or none. Tribology International 36(11), 843-849 (2003). DOI 10.1016/S0301-679X(03)00102-6

21. Podgornik, B., Jacobson, S., Hogmark, S.: Influence of EP additive concentration on the tribological behaviour of DLC-coated steel surfaces. Surface and Coatings Technology 191(2-3), 357-366 (2005). DOI 10.1016/j.surfcoat.2004.04.001

22. Renodeau, H., Papke, B., Pozebanchukz, M. Parthasarathy, P.: Tribological properties of diamond-like carbon coatings in lubricated automotive applications. Proceedings of the Institution of Mechanical Engineers, Part J: Journal of Engineering Tribology 223(3), 405-412 (2009). DOI 10.1243/13506501JET548

23. Ronkainen, H., Varjus, D., Holmberg, K.: Friction and wear properties in dry, water- and oil-lubricated DLC against alumina and DLC against steel contacts. Wear 222(2), 120-128 (1998). DOI 10.1016/S00431648(98)00314-7

24. Topolovec-Miklozic, K., Lockwood, F., Spikes, H.: Behaviour of boundary lubricating additives on DLC coatings. Wear 265(11-12), 1893-1901 (2008). DOI 10.1016/j.wear.2008.04.051

25. Wojciechowski, K., Zybala, R., Mania, R.: Application of DLC layers in 3-omega thermal conductivity method. Journal of Achievements in Materials and Manufacturing Engineering 37(2), 512-517 (2009)

26. Xu, H.: Development of a generalized mechanical efficiency prediction methodology for gear pairs. Ph.D. thesis, Graduate School of The Ohio State University (2005)

27. Yoshida, K., Horiuchi, T., Kano, M., Kumagai, M.: Effect of a tribochemical reacted film on friction and wear properties of DLC coatings. Plasma Processes and Polymers 6(1), S96-S101 (2009). DOI 10.1002/ppap.200930405

28. Zhou, Z., Li, K., Bello, I., Lee, C., Lee, S.: Study of tribological performance of ECR-CVD diamond-like carbon coatings on steel substrates part 2. the analysis of wear mechanism. Wear 258(10), 1589-1599 (2005). DOI 10.1016/j.wear.2004.10.005 